\title{
UAV LIDAR DATA PROCESSING: INFLUENCE OF FLIGHT HEIGHT ON GEOMETRIC ACCURACY, RADIOMETRIC INFORMATION AND PARAMETER SETTING IN DTM PRODUCTION
}

\author{
K. Bakuła ${ }^{1, *}$, M. Pilarska ${ }^{1}$, W. Ostrowski ${ }^{1}$, A. Nowicki ${ }^{1}$, Z. Kurczyński $^{1}$ \\ ${ }^{1}$ Department of Photogrammetry, Remote Sensing and Spatial Information Systems, Faculty of Geodesy and Cartography, \\ Warsaw University of Technology, Warsaw, Poland \\ (krzysztof.bakula, magdalena.pilarska, wojciech.ostrowski, artur.nowicki.stud, zdzislaw.kurczynski)@pw.edu.pl
}

\section{Commission I, WG I/2}

KEY WORDS: lidar, UAV, ULS, geometric accuracy, intensity, DTM, interpolation, resolution

\begin{abstract}
:
This article presents the results of studies related to the impact of flight altitude of UAV equipped with lidar data on geometric and radiometric information. Experiments were conducted in two test areas by performing UAV test flight missions at different UAV Laser Scanner (ULS) altitudes. The results were compared to other parameters describing the point clouds in order to answer the questions related to their genesis and evaluation of a product from such high-resolution datasets. The accuracy of the elevation models was assessed on the basis of control points measured with GNSS RTK and Terrestrial Laser Scanning (TLS). Accuracy was assessed by statistical parameters and differential digital elevation models. The second issue raised in this work is the study of the decrease in radiometric value with an increase in platform elevation. The results of this work clearly indicate the very low impact of platform altitude on DTM vertical error. In presented works the suggestion about DTM resolution and interpolation method are provided. Moreover, the influence of flight height on the reflectance and intensity is notable, however, its impact is related more with the details and resolution of the raster than radiometric values considering the possibility of radiometric calibration of the intensity.
\end{abstract}

\section{INTRODUCTION:}

In recent years, ultralight laser scanners dedicated to unmanned aerial platforms have been developed dynamically. The first UAV laser scanners were relatively heavy compared to today's sensors. Lately, there is a tendency to develop lighter and smaller laser scanners. In Lin et al. (2009), an Ibeo Lux scanner was used, weighing $1.2 \mathrm{~kg}$. Kuhnert and Kuhnert (2013) used a lightweight Hokuyo UTM-30LX sensor, whose weight was $0.37 \mathrm{~kg}$. However, these sensors were of low performance (Jóźków et al., 2016). Pilarska et al. (2016) presented a review of commercial UAV lidar solutions with better performance, though in the year 2020 these solutions are already obsolete. UAV laser scanning (ULS) has provided new possibilities for lidar applications and digital terrain modelling due to the higher density of collected data and more flexible organization of flight missions with lower costs. Additionally, UAV flights can be conducted more often than regular aircraft flights. Digital terrain models generated from dense point clouds containing dozens or even over hundred points per square metre is a product that is very detailed and useful for the inventory of terrain surface. Such dense data can be evaluated in a different way than typical DTM provided as a product of sparse manual measurement or typical airborne lidar point clouds. The quality of the lidar data from UAV platforms is very dependent on the performance of flying missions i.e. altitude above the ground and scanning angle, though it is mainly associated with the scanner and platform used as a tool for collecting data.

The accuracy of data from light UAV laser scanners differs and depends on many factors. Vosselmann and Mass (2010) proposed a complex formula for calculation of the final accuracy of the lidar point cloud from aircraft laser scanners. According to the formula, final measurement accuracy depends on the accuracy of particular components, namely: navigational and positional accuracy (GNSS/INS), laser scanner accuracy (range and incidence angle accuracy), as well as scanner mounting errors (bore-sight and lever-arm errors). In Pilarska et al. (2016), the potential and accuracy of light laser scanners available on the market is presented. In this article, the accuracy of UAVdedicated laser scanners was assessed based on the formula presented in Vosselman and Mass (2010). The results showed that the most important component of errors for scanning systems dedicated to UAVs is IMU unit.

The impact of the flying height may be included in the analysis. In the literature other measures of estimating the altitude accuracy of lidar-based DTM can be found. In contrast to the approach using photogrammetric images, DTM accuracy does not depend so strongly on the altitude of the flight, though the density of lidar points acquires importance. This is shown in the relation proposed by Kraus (2007).

$$
m_{h .}[\mathrm{cm}]=\left(\frac{6}{\sqrt{n}}+120 \operatorname{tg} \alpha\right)
$$

where:

$\mathrm{m}_{\mathrm{h}}$ - average elevation error of DTM,

$\alpha$-slope angle,

$\mathrm{n}-$ density of point cloud (shown in the number of points per parcel size).

It is worth noting that the mentioned dependency is not linear. A density of lidar points that is four times higher causes a doubling in the accuracy of DTM. In the empirical formula (1), there are two constants: 6 and 120. There may be a slightly different estimate of accuracy in the literature, expressed in the different value of these constants, e.g. 6 and 50, which would mean less impact of the slope (Karel, Kraus, 2006).

The density of the initial data (lidar data) determines the resolution of the DTM generated (size of the pixel of the ortophotomap). McCullagh (1988) suggests that the number of

\footnotetext{
* Corresponding author
} 
GRID cells should be (approximately) equal to the number of field points in the area. This means that the GRID cell size can be set as in formula (2):

$$
S=\sqrt{\frac{A}{n}}
$$

where:

$\mathrm{S}$ - cell size of GRID DTM

$\mathrm{n}$ - number of laser points

A - area.

In this paper, the influence of the flight height of the ULS platform on the accuracy of the final products (point clouds and DTM) and radiometric data quality are examined. The parameters of the DTM generation (interpolation and resolution of GRID) will be also discussed in this analysis.

\section{METHODOLOGY AND RESULTS}

The methodology section presents two test areas and describes the data collected with an unmanned aerial system equipped with a lidar unit and a GNSS/INS unit. Reference data is introduced here and finally the scope of the experiment is presented with methods used in the investigation.

\subsection{Test areas}

The first test area is located in Świniary, near Płock city, in central Poland. This is a small village. The second test area is Nietkowice, near Zielona Góra in Western Poland which is located by the Oder River. On both test areas, there is a riverside with levees that are linear objects, and which were successfully mapped using UAV laser scanning.

\subsection{Data tested}

MiniVUX1-UAV - the lidar unit used at both test sites, was launched on the market in 2016 (Figure 1). It has a range of measurement of $330 \mathrm{~m}$ with an approximate maximum flight height above the ground of $160 \mathrm{~m} .360^{\circ}$ field of view and $0.001^{\circ}$ angle resolution make this quite a light sensor $(1.6 \mathrm{~kg})$ that can collect point cloud data with density up to several dozens.

The weight of the fixed-wing platform is almost $11 \mathrm{~kg}$. This platform can be equipped with several sensors due to its useful capacity. A more detailed description of the platform can be found in Bakuła et al. (2019).

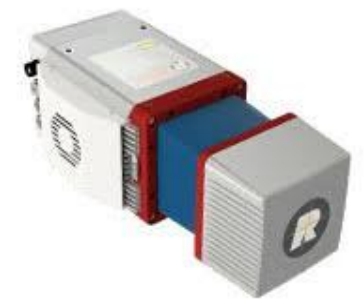

Figure 1. MiniVUX1-UAV scanner by Riegl (www.riegle.com)

\subsection{Reference data}

As reference data, two types of observations were used: GNSS RTK measurements of Ground Control Points (GCP) and cross sections as well as Terrestrial Laser Scanning (TLS) of the levees' surface. GCP were signalised by $0.5 \times 0.5 \mathrm{~m}$ black and white chessboards printed on PCV and placed on the terrain. For each of the chessboards, the central point was measured with
RTK GNSS and used as control points for orientation and then for accuracy assessment of DTM interpolation. The second group of GNSS RTK measurements was points measurement along the levees' cross sections which were selected in order to take into account various types of land cover and slopes. Cross section points were used as independent check points for accuracy assessment of DTM. TLS measurements were acquired only for the first test area, and TLS data were orientated in the national projection system with an accuracy of $0.01 \mathrm{~m}$. An example of TLS data is shown in Figure 2

\begin{tabular}{|c|c|c|}
\hline test area & Świniary & Nietkowice \\
\hline platform & NEO-3 (fixed-wing) \\
\hline lidar unit & miniVUX1-UAV by Riegl \\
\hline reference data & $\begin{array}{c}44 \text { control and } \\
88 \text { check GNSS } \\
\text { RTK points, } \\
\text { TLS }\end{array}$ & $\begin{array}{c}27 \text { control and } \\
107 \text { check GNSS } \\
\text { RTK points }\end{array}$ \\
\hline $\begin{array}{c}\text { average density (two } \\
\text { strips) for flight } \\
\text { heights (AGL): }\end{array}$ & & \\
$80 \mathrm{~m}(1)$ & $12.96 \mathrm{p} . / \mathrm{m}^{2}$ & $15.55 \mathrm{p} . / \mathrm{m}^{2}$ \\
$80 \mathrm{~m}(2)$ & - & $14.65 \mathrm{p} . / \mathrm{m}^{2}$ \\
$100 \mathrm{~m}$ & $10.58 \mathrm{p} . / \mathrm{m}^{2}$ & - \\
$120 \mathrm{~m}$ & $9.59 \mathrm{p} . / \mathrm{m}^{2}$ & $8.07 \mathrm{p} . / \mathrm{m}^{2}$ \\
$180 \mathrm{~m}$ & - & $5.55 \mathrm{p} . / \mathrm{m}^{2}$ \\
\hline filtering software & RiProcess & Terrasolid \\
\hline
\end{tabular}

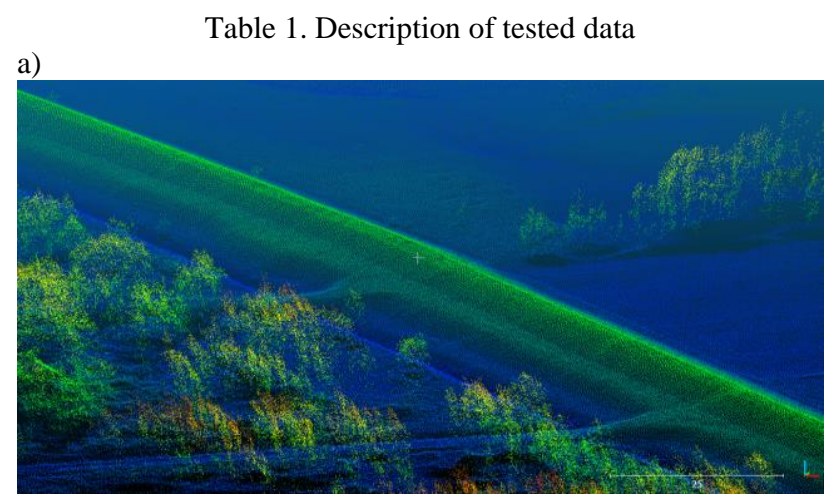

b)

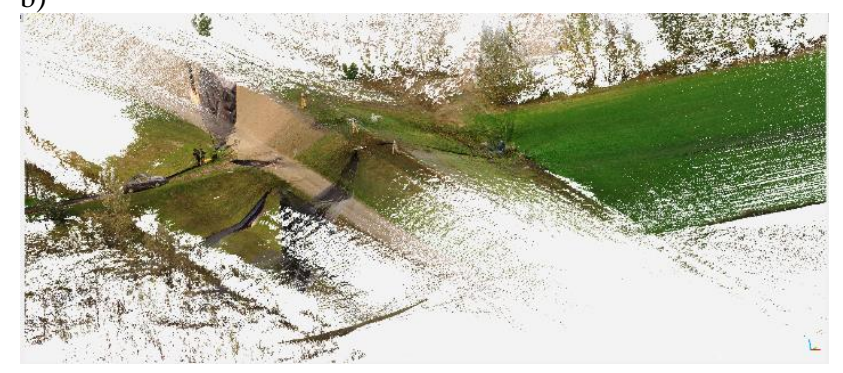

Figure 2. Example of investigated ULS (a) data and TLS (b) data used as reference.

\subsection{Methodology of experiments}

The scope of the experiment is related to ULS data processing. First of all, the influence of data acquisition altitude on the geometric quality of point clouds and on the intensity of the laser beam reflection was analysed. In these analyses, the accuracy of georeferencing of three blocks of data in the two test areas was examined. The accuracy of alignment was analysed, as well as 
deviations on signalized control planes, cross-section check points and differences between ULS and TLS data.

\section{RESULTS}

The results of the experiment are divided into subsections on the impact of height on geometric and radiometric information Recommendations for DTM preparations referred to choose of resolution and interpolation method can be also find here.

\subsection{Flight height influence on geometric accuracy}

Analysis over entire surfaces involved a comparison of the point clouds received from ULS data with data from the TLS point cloud. The results of the comparison with TLS data are shown in Table 2 and visualized in Figure 3. In this comparison, 4 samples of two parts of the embankment were analysed considering flight elevation on the final result of using the cloud-to-cloud distance tool. It can be seen that if a higher flight height is used, no significant decrease in accuracy is observed. Most average distances in the ULS point cloud to TLS are lower than 4 centimetres.

\begin{tabular}{|c|c|c|c|c|}
\hline \multirow{3}{*}{$\begin{array}{l}\text { Flight } \\
\text { height }\end{array}$} & \multicolumn{4}{|c|}{ TLS } \\
\hline & \multicolumn{2}{|c|}{$\begin{array}{c}\text { Sample } 1 \\
\text { (middle of the flight line) }\end{array}$} & \multicolumn{2}{|c|}{$\begin{array}{c}\text { Sample } 2 \\
\text { (middle of the flight line) }\end{array}$} \\
\hline & $\begin{array}{c}\text { average } \\
{[\mathrm{m}]}\end{array}$ & $\begin{array}{l}\text { STD } \\
{[\mathrm{m}]}\end{array}$ & $\begin{array}{c}\text { average } \\
{[\mathrm{m}]}\end{array}$ & $\begin{array}{l}\text { STD } \\
{[\mathrm{m}]} \\
\end{array}$ \\
\hline $80 \mathrm{~m}$ & 0.023 & 0.024 & 0.028 & 0.034 \\
\hline $100 \mathrm{~m}$ & 0.024 & 0.027 & 0.032 & 0.030 \\
\hline \multirow[t]{2}{*}{$120 \mathrm{~m}$} & 0.020 & 0.020 & 0.028 & 0.025 \\
\hline & \multicolumn{2}{|c|}{$\begin{array}{c}\text { Sample } 3 \\
\text { (end of the flight line) }\end{array}$} & \multicolumn{2}{|c|}{$\begin{array}{c}\text { Sample } 4 \\
\text { (end of the flight line) }\end{array}$} \\
\hline $80 \mathrm{~m}$ & 0.010 & 0.013 & 0.008 & 0.012 \\
\hline $100 \mathrm{~m}$ & 0.011 & 0.013 & 0.010 & 0.013 \\
\hline $120 \mathrm{~m}$ & 0.016 & 0.018 & 0.020 & 0.019 \\
\hline
\end{tabular}

Table 2. Comparison of ULS point cloud to TLS data

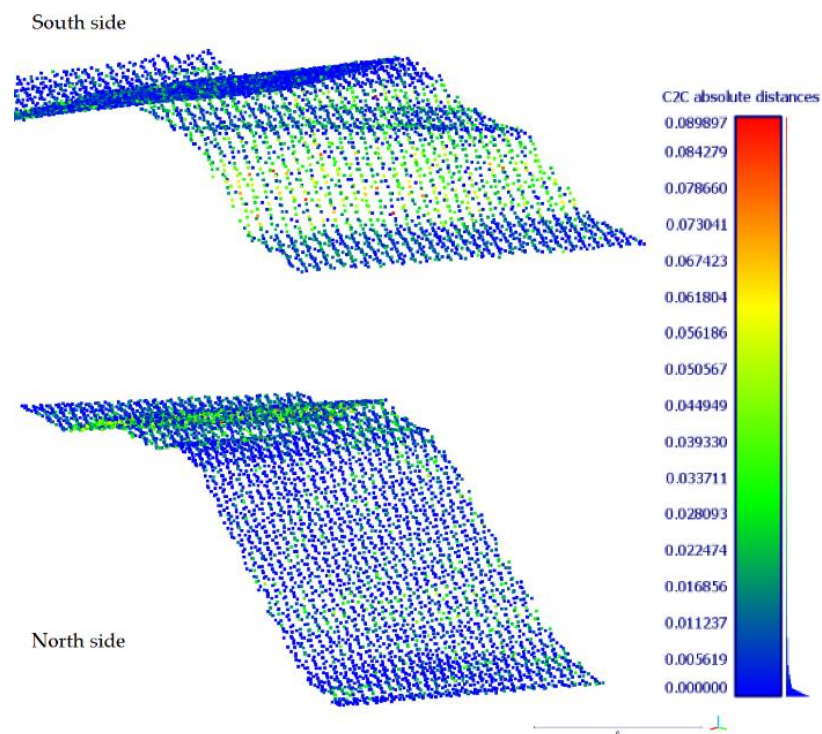

Figure 3. Example of visual comparison of ULS data to TLS for a levee.
The influence of flight height is presented also in Table 4. In this table, considerations about type of interpolation (linear interpolation, binning average) and cell size $(0.25 ; 0.5$ and $1 \mathrm{~m})$ of GRID were included.

The results in Table 3 again confirm that regardless of the interpolation method used, flight altitude does not significantly affect the decrease in DTM accuracy in the analysis of control points. Based on the results in Table 3 , one effect of data acquisition height was noted on the accuracy resulting from the density of the point cloud. Data collected at an altitude of 80 meters are 3 times denser than those at an altitude of 180 metres. This density should not affect the selected DTM cell size according to formula (2).

\begin{tabular}{|c|c|c|c|}
\hline \multicolumn{4}{|c|}{ RMS errors for control points / check points } \\
\hline $\begin{array}{c}\text { GRID } \\
\text { resolution }\end{array}$ & $1 \mathrm{~m}$ & $0.5 \mathrm{~m}$ & $0.25 \mathrm{~m}$ \\
\hline Świniary & \multicolumn{3}{|c|}{ Linear triangulation } \\
\hline $80 \mathrm{~m}$ & $0.026 / 0.027$ & $0.016 / 0.027$ & $0.015 / 0.025$ \\
\hline $100 \mathrm{~m}$ & $0.021 / 0.028$ & $0.019 / 0.026$ & $0.015 / 0.025$ \\
\hline $120 \mathrm{~m}$ & $0.015 / 0.048$ & $0.017 / 0.048$ & $0.011 / 0.048$ \\
\hline Świniary & \multicolumn{3}{|c|}{ Binning average } \\
\hline $80 \mathrm{~m}$ & $0.023 / 0.028$ & $0.013 / 0.031$ & $0.017 / 0.030$ \\
\hline $100 \mathrm{~m}$ & $0.021 / 0.028$ & $0.020 / 0.023$ & $0.022 / 0.027$ \\
\hline $120 \mathrm{~m}$ & $0.018 / 0.050$ & $0.015 / 0.048$ & $0.015 / 0.047$ \\
\hline Nietkowice & \multicolumn{3}{|c|}{ Linear triangulation } \\
\hline $80 \mathrm{~m}(1)$ & $0.070 / 0.094$ & $0.062 / 0.087$ & $0.062 / 0.086$ \\
\hline $80 \mathrm{~m}(2)$ & $0.078 / 0.090$ & $0.067 / 0.094$ & $0.067 / 0.093$ \\
\hline $120 \mathrm{~m}$ & $0.060 / 0.114$ & $0.056 / 0.111$ & $0.059 / 0.111$ \\
\hline $180 \mathrm{~m}$ & $0.070 / 0.103$ & $0.061 / 0.103$ & $0.060 / 0.102$ \\
\hline Nietkowice & \multicolumn{3}{|c|}{ Binning average } \\
\hline $80 \mathrm{~m} \mathrm{(1)}$ & $0.068 / 0.092$ & $0.059 / 0.087$ & $0.055 / 0.081$ \\
\hline $80 \mathrm{~m}(2)$ & $0.069 / 0.094$ & $0.063 / 0.093$ & $0.055 / 0.089$ \\
\hline $120 \mathrm{~m}$ & $0.054 / 0.113$ & $0.052 / 0.108$ & $0.058 / 0.108$ \\
\hline $180 \mathrm{~m}$ & $0.062 / 0.102$ & $0.060 / 0.101$ & $0.059 / 0.100$ \\
\hline
\end{tabular}

Table 3. RMS errors on check points in comparison to different GRID size and interpolation method of DTM generated from ULS data

\subsection{Flight height influence on radiometric information}

Referring to intensity information and its relation to flight height, the miniVUX-UAV1 scanner allows recording echo intensity information at three different attributes. The first is intensity value (Amplitude) which is the integer representation of the pulse return magnitude. The second is Riegl amplitude (_Amplitude) which is the logarithms of ratio given in the units of decibel of optical input power and minimum detectable input power. The third is reflectance (_Reflectance) that includes calibration using ratio of the actual amplitude of that target to the amplitude of a white flat target at the same range, orientated orthonormal to the beam axis, and with a size in excess of the laser footprint. (Riegl, 2017).

All three rasters of radiometric information are presented in Figure 4. It shows the influence of flight height on the radiometry value for intensity, reflectance and amplitude. For other rasters, values for intensity and reflectance were different due to the lower resolution of the point cloud. 


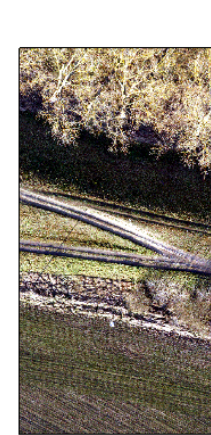

orthomosaic

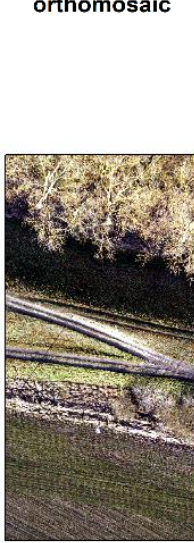

orthomosaic

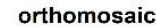

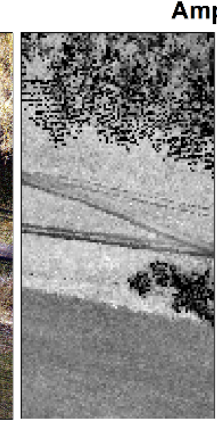

$80 \mathrm{~m}$
Amplitude

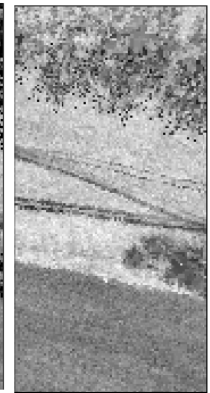

$120 \mathrm{~m}$

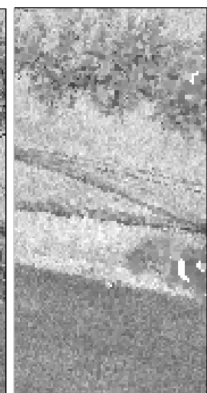

$180 \mathrm{~m}$
High : 42000 20 $40 \mathrm{~m}$

Amplitude

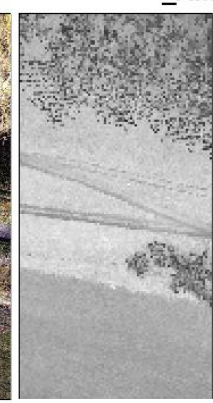

$80 \mathrm{~m}$

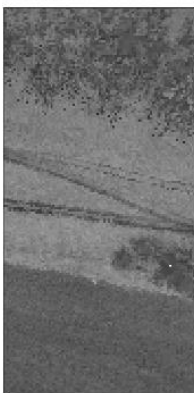

$120 \mathrm{~m}$ High : 20
Low : 3 20
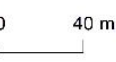

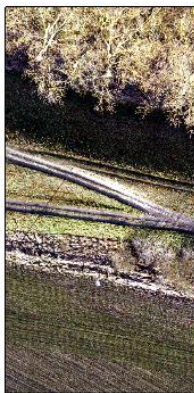

orthomosaic

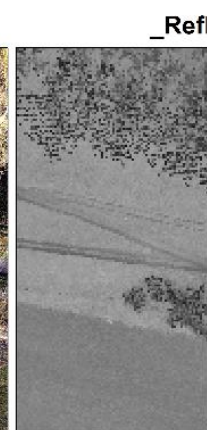

$80 \mathrm{~m}$

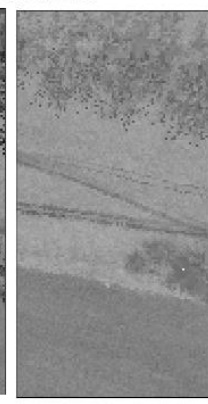

$120 \mathrm{~m}$

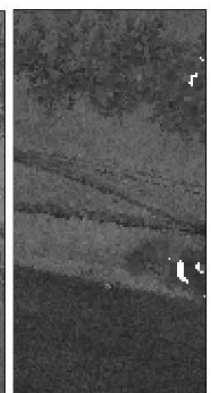

$180 \mathrm{~m}$ $40 \mathrm{~m}$
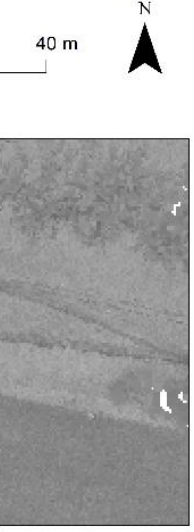

$180 \mathrm{~m}$

Figure 4. Intensity, amplitude and reflectance of ULS data for three flight heights (Nietkowice test area).

Analysing Figure 4 it can be noticed that the lower the image sharpness, the higher the flight altitude. This is related to the decrease in the density of the point cloud. This shows the undeniable effect of height on the detail of the intensity images.

It is worth noting that there are also differences in the intensity value extremely visible for different altitudes in case of _Amplitude raster. To examine it thoroughly, polygon areas of low grass vegetation (grass) and uncovered bare ground were selected, point clouds from two strips were separated and histograms of a radiometric value were counted and analysed. Basic statistics such as mean value and standard deviations are included in Table 4. These values are also shown in Figure 5.

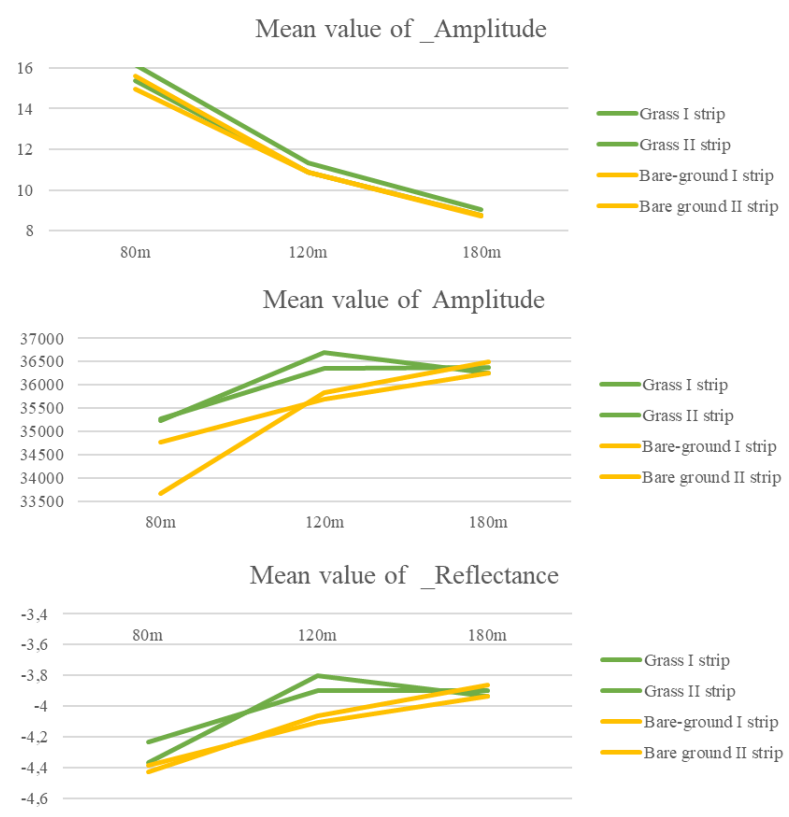

Figure 5. Intensity, amplitude and reflectance of ULS data for three flight heights for bare ground and grass polygon (Nietkowice test area).

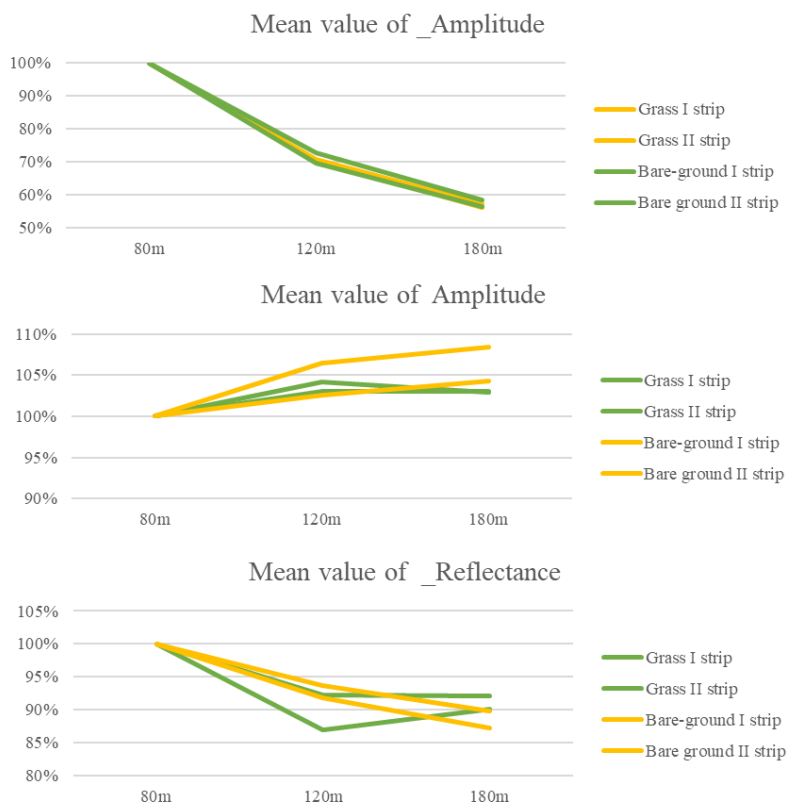

Figure 6. Percent value change for intensity, amplitude and reflectance of ULS data for three flight heights for bare ground and grass polygon (Nietkowice test area).

The charts in Figure 5 show changes in the absolute values for all intensity rasters obtained from the lidar scanner. Changes in the raster value for the bare ground and grass polygon are clearly discernible, however, in the case of _Reflectance and Amplitude the range of these changes is very limited - less than $5 \%$ for Amplitude and less than $15 \%$ for_Reflectance when the values for the highest and the lowest flight altitude are considered. The changes for_Amplitude raster are much more significant and decrease in value by more than $40 \%$. It is clearly seen in Figure 6 presenting percent of intensity value change with reference to the lowest flight altitude. 


\begin{tabular}{|c|c|c|c|c|c|c|c|}
\hline & Altitude & $\begin{array}{c}\text { Mean } \\
\text { Amplitude } \\
\end{array}$ & $\begin{array}{c}\text { STD } \\
\text { Amplitude }\end{array}$ & $\begin{array}{c}\text { Mean } \\
\text { Reflectance }\end{array}$ & $\begin{array}{c}\text { STD } \\
\text { Reflectance } \\
\end{array}$ & $\begin{array}{c}\text { Mean } \\
\text { Amplitude }\end{array}$ & $\begin{array}{c}\text { STD } \\
\text { Amplitude } \\
\end{array}$ \\
\hline \multirow{3}{*}{$\begin{array}{l}\text { Grass } \\
1^{\text {st }} \text { strip }\end{array}$} & $80 \mathrm{~m}$ & 16.141 & 0.759 & -4.233 & 0.533 & 35280.363 & 1748.012 \\
\hline & $120 \mathrm{~m}$ & 11.349 & 0.631 & -3.902 & 0.528 & 36363.297 & 1730.026 \\
\hline & $180 \mathrm{~m}$ & 9.051 & 0.631 & -3.901 & 0.582 & 36366.991 & 1907.303 \\
\hline \multirow{3}{*}{$\begin{array}{c}\text { Grass } \\
2^{\text {nd }} \text { strip }\end{array}$} & $80 \mathrm{~m}$ & 15.372 & 1.169 & -4.37 & 0.733 & 35225.011 & 2402.256 \\
\hline & $120 \mathrm{~m}$ & 10.87 & 0.663 & -3.801 & 0.526 & 36694.731 & 1723.107 \\
\hline & $180 \mathrm{~m}$ & 8.789 & 0.825 & -3.936 & 0.724 & 36255.081 & 2371.146 \\
\hline \multirow{3}{*}{$\begin{array}{l}\text { Bare- } \\
\text { ground } \\
1^{\text {st }} \text { strip }\end{array}$} & $80 \mathrm{~m}$ & 14.938 & 1.577 & -4.43 & 1.142 & 33666.732 & 3741.573 \\
\hline & $120 \mathrm{~m}$ & 10.856 & 0.786 & -4.065 & 0.69 & 35831.852 & 2259.979 \\
\hline & $180 \mathrm{~m}$ & 8.719 & 0.877 & -3.863 & 0.717 & 36492.202 & 2350.968 \\
\hline \multirow{3}{*}{$\begin{array}{l}\text { Bare } \\
\text { ground } \\
2^{\text {nd }} \text { strip }\end{array}$} & $80 \mathrm{~m}$ & 15.611 & 1.154 & -4.385 & 0.822 & 34781.318 & 2692.993 \\
\hline & $120 \mathrm{~m}$ & 10.878 & 0.79 & -4.109 & 0.691 & 35687.694 & 2264.004 \\
\hline & $180 \mathrm{~m}$ & 8.789 & 0.825 & -3.936 & 0.724 & 36255.081 & 2371.146 \\
\hline
\end{tabular}

Table 4. Intensity histogram statistics for bare ground and grass polygon in the Nietkowice test area

It should be also noted that while analysing intensity values from two separate lidar strips, these values are quite consistent for all rasters, with a difference of less than 5\% for_Amplitude, less than 3\% for_Reflectance and less than 1\% for Amplitude. The small difference in intensity images in the last raster is due to the fact that all corrections related to signal propagation and radiometric calibration have already been included in this intensity raster.

\section{DISUSSION AND CONCLUSION}

In this paper, a simple investigation considering the influence of the flight height of UAV equipped with a lidar unit was carried out. According to the results it was confirmed that flight height does not have a significant impact on the accuracy of ULS data which is also the conclusion coming from Kraus (2007) for typical high-altitude airborne laser scanning. However, flight height has an influence on the point cloud density, which determines the accuracy and detail of the digital terrain models and intensity rasters.

Regarding the analysed data for the two test areas in which the data were acquired from different heights, there was no significant difference in the accuracy of the digital elevation models. In experiments conducted for flight height from 80 to 180 metres, it was confirmed that ULS can provide DTM in the accuracy within a 3 to $10 \mathrm{~cm}$ range depending on model resolution and interpolation method. These results are comparable with those investigations where flight altitudes were much lower - mostly less than $50 \mathrm{~m}$ (Salach et al, 2018; Lin et al., 2019; Resop et al., 2019).

Low differences of vertical error of DTM between parameter settings may also result from slight differences in flight heights. The limitation is the range of the scanners, which prevents significant height differences in the compared data. Therefore, it can be assumed that in the case of low-altitude ULS data, the laser scanning height has no significant impact on the accuracy of the final point cloud and DTM, however it does affect the data detail represented by the density of the point cloud and the possible GRID of DTM. Analysing the influence of data acquisition altitude on radiometric information, the expected decrease in amplitude can be observed, however, the reflectance values are quite constant, proving that these values are free from the range influence what can be useful in works using intensity information in detection of selected objects (Lin et al., 2019).

While processing ULS data with densities higher than a few points per square metre, adequate resolutions of the DTMs should be applied for the given density of a point cloud. Height accuracy of the DTM product will not matter as it is limited by the parameters of the scanner and IMU. For point clouds with a density of several points per square metre, the higher spatial resolution of DTM was able to improve the accuracy of the resulting product with an increase of up to $1-2 \mathrm{~cm}$, however this model resolution is limited by point density.

\section{ACKNOWLEDGMENT}

The presented results were obtained within the framework of the project "Advanced technologies in the prevention of flood hazard (SAFEDAM)", financed by the National Centre for Research and Development in Defence, Security Programme. The authors would like to thank MSP Innotech for their co-operation with photogrammetric works and for providing the UAS images and laser scanning data used in the presented study.

\section{REFERENCE}

Bakuła, K., Ostrowski, W., Pilarska, M., Szender, M., Kurczyński, Z., 2019: Evaluation and calibration of fixed-wing multisensor UAV mobile mapping system: improved results. International Archives of the Photogrammetry, Remote Sensing \& Spatial Information Sciences, XLII-1, 189-195. https://doi.org/10.5194/isprs-archives-XLII-2-W13-189-2019.

McCullagh, M. J., 1988: Terrain and surface modelling systems: theory and practice. Photogrammetric Record, 12 (72), 747-779.

Karel W., Kraus K., 2006: Quality parameters of Digital Terrain Models. EuroSDR Official Publication No 51., 125-139.

Jozkow, G., Toth, C., Grejner-Brzezinska, D., 2016: UAS topographic mapping with velodyne LiDAR sensor. ISPRS Annals of the Photogrammetry, Remote Sensing and Spatial Information Sciences, 3, 201-208. doi:10.5194/isprsannals-III-1201-201.

Kuhnert, K. D., Kuhnert, L., 2013. Light-weight sensor package for precision 3D measurement with micro UAVs EG power-line 
monitoring. Int. Arch. Photogramm. Remote Sens. Spat. Inf. Sci, XL-1/W, 235-240.

Lin, Y., Hyyppa, J., Jaakkola, A., 2011. Mini-UAV-borne LIDAR for fine-scale mapping. IEEE Geoscience and Remote Sensing Letters, 8(3), 426-430.

Lin, Y. C., Cheng, Y. T., Zhou, T., Ravi, R., Hasheminasab, S. M., Flatt, J. E., ..., Habib, A., 2019: Evaluation of UAV LiDAR for Mapping Coastal Environments. Remote Sensing, 11(24), 2893. https://doi.org/10.3390/rs11242893.

Li, Z., Cheng, C., Kwan, M. P., Tong, X., Tian, S., 2019: Identifying asphalt pavement distress using UAV LiDAR point cloud data and random forest classification. ISPRS International Journal of Geo-Information, 8(1), 39.

Pilarska, M., Ostrowski, W., Bakuła, K., Górski, K., Kurczyński, Z., 2016: The potential of light laser scanners developed for unmanned aerial vehicles-the review and accuracy. The International Archives of Photogrammetry, Remote Sensing and
Spatial Information Sciences, XLII-2/W2, 87-95. doi:10.5194/isprs-archives-XLII-2-W2-87-20.

Resop, J. P., Lehmann, L., Hession, W. C., 2019: Drone Laser Scanning for Modeling Riverscape Topography and Vegetation: Comparison with Traditional Aerial Lidar. Drones, 3(2), 35. https://doi.org/10.3390/drones3020035.

RIEGL Laser Measurement Systems GmbH, 2017. LAS Extrabytes Implementation in RIEGL Software Whitepaper.

Salach, A., Bakuła, K., Pilarska, M., Ostrowski, W., Górski, K., Kurczyński, Z., 2018: Accuracy assessment of point clouds from LidaR and dense image matching acquired using the UAV platform for DTM creation. ISPRS International Journal of GeoInformation, 7(9), 342. https://doi.org/10.3390/ijgi7090342.

Vosselman, G., Maas, H-G., 2010. Airborne and Terrestrial Laser Scanning, CRC press. 